\title{
Particle Sizing, Not Otherwise Specified
}

National Cancer Institute

\section{Source}

National Cancer Institute. Particle Sizing, Not Otherwise Specified. NCI Thesaurus. Code C113039.

A particle sizing operation not otherwise specified. 